\title{
Evaluating Effectiveness of Best Management Practices to Control Accelerated Sedimentation of the Morro Bay Estuary
}

\author{
Misgana Muleta, Ph. D., P.E.
}

The Morro Bay estuary, located on the central Coast of California approximately half way between Los Angeles and San Francisco, is one of the most important wetlands on the west Coast as it supports wide variety of habitats including numerous sensitive and endangered plant and animal species. Various studies have identified accelerated erosion and subsequent sedimentation as a major threat for sustainability of the bay. Watershed disturbances caused by agricultural activities are believed to be one of the major causes of the accelerated erosion and sedimentation. More than 200 conservation practices have been installed in the watershed since the mid-1990 to reduce erosion and sedimentation. This paper will review the implemented BMPs and will evaluate effectiveness of the BMPs using observations and modeling exercise. Streamflow and sediment concentration, measured mainly during the rainy seasons, are available for multiple locations in the watershed. However, the observations are not sufficient in terms of spatial density and data length to evaluate effectiveness of the mitigation measures at various locations in the watershed. It would be daunting in terms of cost to develop an intensive network of monitoring sites that would be needed for reliable management of NPS pollutants. As a result, comprehensive watershed simulation models that integrate watershed and climate characteristics and can estimate pollutant quantity at various locations, and that can also identify source of the contaminants, is emerging as a key component of watershed management. In this regard, a comprehensive watershed simulation model for the Morro Bay watershed has been developed using Soil and Water Assessment Tool (SWAT) to simulate both streamflow and sediment concentration. The observed data was used to improve prediction accuracy of the SWAT model through parameter sensitivity analysis and calibration steps. Parameter sensitivity analysis was performed using step-wise-regression analysis and Morris's one-at-a time (OAT) method. Calibration was performed using four different optimization methods: PEST, Genetic Algorithms, the Shuffled Complex Evolution Algorithm, and Dynamically Dimensioned Search. Relative performance of the sensitivity analysis methods and the calibration algorithms will be discussed in terms of effectiveness and computational efficiency. The developed model was used to evaluate effectiveness of the BMPs implemented in the Morro Bay watershed, and can also be used to prioritize sites where BMPs may be implemented in the future to further improve ecological integrity of the estuary.

\section{Introduction}

Nonpoint source (NPS) pollution caused by anthropogenic activities such as agriculture and urbanization is the leading cause of water quality impairment in the United States. Over the years, substantial efforts have been made by various government agencies to minimize NPS pollution. For example, section 303(d) of the Clean Water Act requires state and local agencies to develop and implement Total Maximum Daily Loads (TMDLs) for impaired waters. Numerous streams in California and other states require TMDL development for various NPS pollutants such as sediment, nutrients, pesticides and metals. Quantifying NPS pollutants and 
identifying the sources as the pollutants exhibit spatial and temporal variability depending on land use, soil, topography and rainfall characteristics of the watershed making TMDL development process more difficult. Monitoring program can assist in quantifying contaminant concentration at several critical locations. However, implementing a monitoring program that is dense enough to reliably manage NPS pollution will not be cost effective. Alternatively, a hydrologic and water quality model that accounts for all factors that affect NPS pollution such as soil type, weather, land use, and topography of the watershed, and that can estimate concentration of pollutants at sufficient spatial and temporal scale can be used as a decision support tool to manage NPS pollution from complex agricultural as well as urban watersheds. Once developed, watershed simulation models can be used to identify contaminant source areas, locate "hot spot" reaches of the stream that have high pollution risk, identify optimal locations where monitoring efforts need to be focused thus optimizing cost of monitoring, and determine BMPs that can best reduce the contaminant of concern. Models can forecast effect of changing trends in land use, climate, use of agricultural chemicals, and other farm management practices on streamflow and NPS pollution.

Functionality of hydrologic simulation models can be further enhanced if coupled with other decision support tools. For example, a watershed simulation model can be integrated with systems analysis tools such as optimization models (Muleta and Nicklow, 2005b) to determine optimal set of best management practices that reduce NPS pollution and meet regulations such as TMDLs with least cost. Coupled hydrologic and ecosystem models can be used to determine the impact of individual contaminants such as pesticides on aquatic life (e.g., fish or endangered aquatic animal) and help develop holistic environmental management plans and operations at the watershed scale. Watershed simulation models, when used along with models that predict the impact of climate change on regional precipitation and temperature, can help estimate climate change impact on streamflow, NPS pollution, and ecosystem health of the watershed under various climate change scenarios. As a step towards developing a multidisciplinary and comprehensive decision support system for planning and management of water resources systems, the objective of this study was to develop a watershed simulation model for Morro Bay watershed located on the central Coast of California and to assess effectiveness of BMPs that have been installed in the watershed to reduce sedimentation of the estuary.

For watershed simulation models to be useful for applications ranging from academic research to major policy analysis, models and modeling processes should be scientifically sound, robust, reproducible and defensible (U.S. EPA, 2002). However, since every mathematical model undergoes some level of conceptualization and parameterization, models must pass through rigorous model evaluation procedure before they are utilized as decision making aid in the planning and management of water resources. Many methodologies have been developed for model evaluations over the years (Duan et al., 1992; Beven and Freer, 2001; Muleta and Nicklow, 2005; Tolson and Shoemaker, 2007). The major limitation of the existing model evaluation methods is their computational inefficiency. Depending on the problem size, it could take weeks to months of CPU time to calibrate a comprehensive watershed simulation model thus threatening their practicality for day-to-day applications. This study explores the application of a comprehensive hydrologic and water quality simulation model known as Soil and Water Assessment Tool (Arnold et al., 1999) to control nonpoint source pollution of a sensitive freshwater estuary on the Central Coast of California. Sediment is the major contaminant of concern that has been threatening sustainability of the estuary. Three sensitivity analysis (SA) and four automatic model calibration methods have been applied to improve accuracy of 
streamflow and sediment predicted for the watershed draining the Bay. The SA methods are compared in terms of computational efficiency, consistency of the identified sensitive parameters, and the quality of information available for the modeler to decide what parameters to include in the model calibration stage. The four calibration methods are also compared in terms of their accuracy in reproducing observed streamflow, and in terms of their computational efficiency. This comparative study can assist other modelers select effective and efficient SA and calibration methods among the methods tested in this study. Finally, the developed model is used to identify major sediment sources in the Morro Bay watershed, and to evaluate effectiveness of the best management practices (BMPs) that have been implemented in the watershed since mid-1990 to control sedimentation of the bay.

\section{The Watershed Simulation Model}

SWAT, a model developed at the USDA's Blacklands research center, is a continuous-time, spatially distributed simulator developed to assist water resource managers in predicting impacts of land management practices on water, sediment and agricultural chemical yields. The model is well suited for large complex watersheds with varying soils, land use and management conditions over long periods of time (Nietsch, et al., 2001; Arnold et al., 1998; ASCE, 1999). SWAT makes use of watershed information such as weather, soil, topography, vegetation, and land management practices to simulate watershed processes such as surface and subsurface flow; erosion and sedimentation of overland as well as channel flows; crop growth for user specified agricultural management practices, and nutrient cycling for various species of nitrogen and phosphorus, among others. The model commonly operates on daily time scale. Spatially, the model subdivides a watershed in to subwatersheds, or subbasins, based on topographic information of the watershed. The subwatersheds could be further classified into spatial modeling units known as hydrologic response units (HRUs) depending on heterogeneity of the land uses and soil types within the subbasins. At the scale of an HRU, watershed variables such as soil types and properties, land use and related management features, weather, and topographic parameters would be considered homogeneous. As a distributed model, a major concern that may arise regarding the practicality of SWAT may be its data requirements. For the U.S., fortunately the data required (e.g., soil, land use, topography, and weather) are commonly available from government agencies (Nietsch, et al., 2001). For watersheds that lack weather data, the model has a stochastic weather simulator that generates synthetic data based on monthly weather statistics derived from long-term records available from a station geographically located near the watershed. In addition, the model operates on an ArcGIS@ platform, which greatly assists in the generation of model input parameters. All these comprehensive features make SWAT an ideal choice for use in integrative watershed management systems.

\section{The Study Watershed and Data}

The Morro Bay watershed located on the Central Coast of California has been used to demonstrate the SA and the calibration methods considered in this study. Two creeks, Los Osos and Chorro, drain this $196 \mathrm{~km}^{2}$ watershed into the bay that supports a variety of marine habitats, commercial and sport fishing, shellfish harvesting and recreational activities. The watershed consists of two urban areas, cropland, rangeland, and a wide variety of natural habitats including marsh, oak woodland, riparian, and dunes. The Morro Bay estuary has been impacted by NPS 
pollution including sediment, bacteria, metals, and nutrients (CCRWQCB, 2002). Sediment has been identified as the major pollutant of concern. To properly simulate hydrologic and water quality fluxes of a watershed, SWAT requires topographic, soil, land use and climate data in addition to observed streamflow and water quality data that is used for calibration. Accordingly, the data that have been obtained for the study watershed include daily rainfall for Morro Bay Fire station from the National Climatic Data Center and other climate data including daily minimum and maximum temperature, wind speed, humidity, and solar radiation obtained from California Irrigation Management Information System (CIMIS) for a station at California Polytechnic State University (Cal Poly) campus. A 10-m resolution DEM and 30-m resolution land use map were obtained from the United States Geological Survey (USGS), and 30-m resolution soil map was obtained from the Natural Resources Conservation Service (NRCS). In addition, streamflow data for three sites in the watershed were obtained from the San Luis Obispo County Public Works, and sediment concentration and streamflow data at additional two sites in the watershed were obtained from previous study conducted by the Central Coast Regional Water Quality Control Board and Cal Poly (CCRWQCB, 2002). Only the Chorro Creek watershed (about $112 \mathrm{~km}^{2}$ ) was modeled in this study as it has been identified as the major source of sediment to the estuary (CCRWQCB, 2002).

\section{Best Management Practices Implemented in the Study Watershed}

Over 245 best management practices have been installed in the Morro Bay watershed in order to restore and maintain the hydrological and biological integrity of the estuary (CCRWQCB, 2002). The conservation practices include sediment capture (retention) projects, ranch and farm conservation practices, grazing management, cattle exclusion, stream bank stabilization, fencing, filter strips, vegetated buffer strips, critical area planting, grassed waterways, lined waterways , road improvements, and others (CCRWQCB, 2002). The site of the major best management projects is shown in Figure 1, and these major BMPs are briefly described below. 


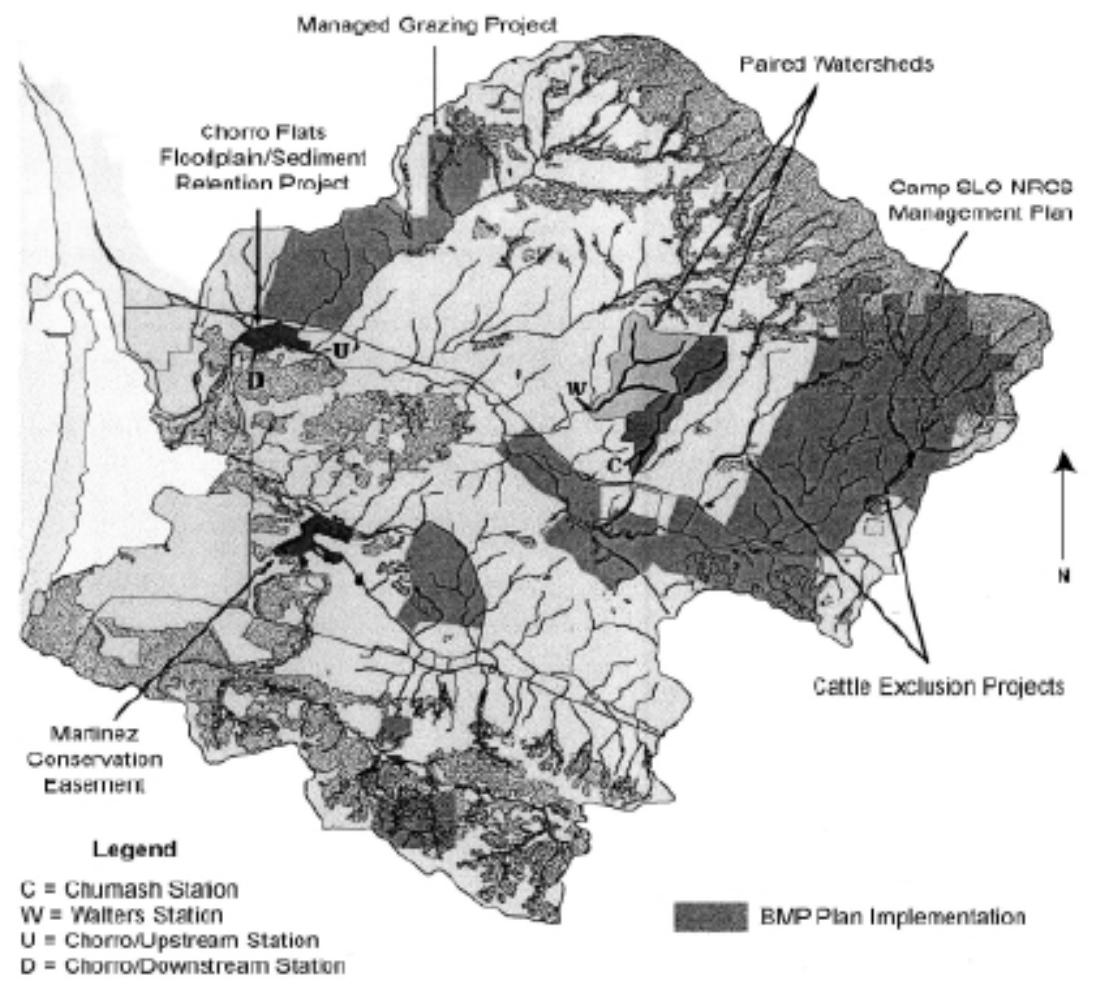

Figure 1: Map of the Morro Bay Watershed and Site of the Major BMPs (Source: CCRWQCB and Cal Poly, 2003).

\section{Chorro Flats Sediment Retention Project}

Located near the mouth of Chorro Creek (see Figure 1), the Chorro Flats Enhancement Project is designed to reduce sediment entering the bay from Chorro Creek by allowing the Creek to overflow its main channel and deposit the sediment on the floodplain. The project also restores and enhances wetland and wildlife habitat, provides some public education opportunities, and continued agricultural operations which will emphasize environmentally sensitive agricultural practices (CSLCRCD, 2002). Since this 120-acre project construction was finalized in 1997, many instream and bank restoration efforts have been pursued. The current condition of the project is an increasingly stable channel with a gradual progression towards a mature and functioning riparian corridor (CCRWQCB and Cal Poly, 2003). A study by the San Luis Coastal Resource Conservation District (CSLCRCD, 2002) showed that approximately 23\% of the total load and $85 \%$ of the bed-load from Chorro Creek was captured on Chorro Flats.

\section{Cattle Exclusion Projects}

Rangeland is the major land use in the Morro Bay watershed and it is often used for grazing purposes without the protection of the creek corridor. The cattle exclusion projects are designed to reduce erosion of the riparian areas including bank erosion by limiting/avoiding cattle access to the creek by fencing the riparian areas. Re-vegetation of the riparian areas has also been used to restore the vegetation and reduce bank erosion. Cattle exclusion projects were installed in the upper Chorro Creek and in the Diary Creek as shown in Figure 1. 


\section{Managed Grazing Projects}

Managed grazing projects refer to activities such as creating smaller pastures for better management of cattle grazing and grazing rotations through the pastures to reduce the number of grazing days per pasture thus minimizing erosion and sedimentation from the land. Grazing management operations control cattle movement through smaller pastures thus creating intensive grazing rotation/rest system. The strategy manages the cattle and the land together in order to increase biodiversity, maximize forage quality and production, decrease bare ground and erosion and maintain integrity of land for watershed protection and wildlife (CCRWQCB and Cal Poly, 2003). Managed grazing projects were implemented in Chumash Creek watershed and San Bernardo Creek watershed (see Figure 1).

\section{Paired Watershed Study}

The Central Coast Regional Water Quality Control Board (CCRWQCB) and the California State Polytechnic University (Cal Poly) conducted best management effectiveness study, known as paired watershed study, from 1992-2002 on Walters Creek and Chumash Creek subwatersheds (see Figure 1). Various BMPs were installed in Chumash Creek watershed starting from 1995 whereas no BMPs were implemented in the Walters Creek watershed to use it as a control watershed. The BMPs installed in the Chumash watershed include grazing management, stream bank stabilization, cattle exclusion projects and planting native riparian trees along select stream banks. Streamflow, sediment yield and various water quality parameters were monitoring during the rainy season for both Walters Creek and Chumash Creek over the 10-yr duration of the study. Effectiveness of the BMPs installed in the Chumash Creek watershed was analyzed using the pre-BMP and post-BMP data collected at Chumash Creek watershed, as well as by comparing Walters Creek data with Chumash Creek data. The data collected during the paired watershed study was study in this work to calibrate and validate sediment yield.

\section{Research Methodology}

The main objective of this study was to analyze effectiveness of the BMPs implemented in the Morro Bay watershed to reduce sedimentation of the estuary and protect hydrological and ecological integrity of the bay. Ideally, the research objective would be best served by monitoring streamflow, sediment yield and other water quality parameters at several strategic sites in the watershed. However, since sufficient monitoring data is not available for the watershed, modeling approach has been pursued in this study. A comprehensive watershed simulation model known as SWAT has been selected for the study. Model evaluation exercise including sensitivity analysis and model calibration has been conducted. Sensitivity analysis has been performed using Morris's one-at-a-time (OAT) method and stepwise regression analysis method. Calibration was performed using genetic algorithms, Shuffled Complex Evolution, Dynamically Dimensioned Search and PEST. Streamflow was calibrated and validated using data obtained from the San Luis Obispo County Department of Public Works for a station at Canet Road. Sediment yield was calibrated using the data collected during the paired watershed study at Walters Creek station and validated on the pre-BMP sediment yield measured at the Chumash Creek station. The calibrated model was used to estimate sediment generated from the Chorro Creek watershed. Appropriate model parameters were adjusted (modified) for the sites 
where BMPs were installed to determine effectiveness of the BMPs in reducing erosion and sediment generation. Sediment generated from the watershed were determined using the with BMPs and the without BMPs scenarios to evaluate effectiveness of the BMPs. Since both Walters Creek and Chumash Creek watersheds are located on the upper portion of the watershed, the calibrated model does not properly simulate sediment deposition and scouring processes for the Chorro Creek watershed. As such, the calibrated model is not expected to accurately estimate the sediment yield (sediment that leaves) the Chorro Creek watershed and enters the Morro Bay watershed.

\section{Sensitivity Analysis Methods and Application Results}

For distributed watershed models like SWAT that are designed to account for spatial variability of watershed characteristics on hydrologic and water quality outputs, the number of conceptual parameters that need to be calibrated is substantially large, especially when compared to lumped conceptual models where model parameters are averaged over the watershed. The increase in the number of parameters makes calibration of distributed watershed models more challenging. Depending on the characteristics of the study watershed, however, streamflow and water quality outputs may not be equally sensitive to all parameters. SA, which refers to the process of determining the relative importance of individual model parameters on output uncertainty, is an essential component of model evaluation as it helps reduce the number of parameters that need to be calibrated. In this study, a modified form of one-factor- at-a-time (Morris, 1991) that has been implemented in SWAT (Griensven, et al, 2006) and a global SA method that uses sampling based multiple regression approach (Muleta and Nicklow, 2005) are compared in terms of their effectiveness in screening important SWAT parameters that need to be calibrated for the study watershed. The reader is referred to Muleta (2010) for details on the SA methods and application methodology.

Results of the two SA methods for streamflow at Canet Road station is given in Table 1. For the stepwise regression method (SRM), the Table provides the input factors selected at the final step of the regression model, along with the $R^{2}$ of the regression model constructed using the input factor(s) selected at the final step, and the standardized regression coefficient (SRC) and $p$-value of each input factor. For OAT, Table 1 shows the rank that the top nine parameters are assigned based on the magnitude of the mean sensitivity index, and the mean and the variance of the sensitivity index. For definition of the input parameters listed in Table 1 and their role in streamflow simulation, the reader is referred to Neitsch et al. (2005) and Muleta and Nicklow (2005). Comparison of the SA results given in Table 1 shows that overall the two SA methods produced consistent results. Eight of the nine input parameters selected by SMR were also ranked in the top nine by the OAT. However, there is noticeable difference in the relative importance of some of the parameters. For example, Alpha_Bf is identified as the most important parameter by OAT, and it was ranked $9^{\text {th }}$ by SMR. This may be due to its high variance as determined by OAT (see Table 1). One of the drawbacks of the OAT approach is that the method generates only relative importance of the parameters. It lacks a quantitative measure that can be used to decide how many parameters to consider for the calibration step thus making the decision subjective. SMR overcomes this limitation as it uses several stopping criteria to help decide the cutoff point. Over all, the application shows that either of the two SA methods could be used to identify the most influential parameters of SWAT that need to be calibrated to improve streamflow simulation accuracy of the model. Based on these SA results, the top nine parameters 
identified by OAT and SMR (i.e., a total ten parameters) have been considered to calibrate streamflow for the study watershed.

Table 1: Sensitivity Analysis Results for SRM and OAT Methods

\begin{tabular}{|c|c|c|c|c|c|c|c|}
\hline \multicolumn{4}{|c|}{ SMR Results } & \multicolumn{4}{|c|}{ OAT Results } \\
\hline Parameter & SRC & P-Value & $\mathbf{R}^{2}$ & Parameter & Rank & Mean & Variance \\
\hline $\mathrm{Cn} 2$ & 0.7236 & 0.0000 & \multirow{9}{*}{0.7073} & Alpha_Bf & 1 & 1.26563 & 26.10857 \\
\hline Esco & 0.2670 & 0.0000 & & $\mathrm{Cn} 2$ & 2 & 1.25889 & 1.84401 \\
\hline Sol_z & -0.2192 & 0.0000 & & Sol_z & 3 & 0.95305 & 4.69416 \\
\hline Sol_Awc & -0.1994 & 0.0000 & & Esco & 4 & 0.48438 & 0.49405 \\
\hline Sol k & 0.0940 & 0.0004 & & Sol_Awc & 5 & 0.36604 & 0.02375 \\
\hline Gwqmn & -0.1005 & 0.0002 & & Sol_k & 6 & 0.11986 & 0.00260 \\
\hline Slope & 0.0656 & 0.0133 & & Slope & 7 & 0.11195 & 0.00180 \\
\hline Blai & -0.0619 & 0.0192 & & Revapmn & 8 & 0.07873 & 0.12218 \\
\hline Alpha_Bf & 0.0517 & 0.0494 & & Blai & 9 & 0.06924 & 0.00586 \\
\hline
\end{tabular}

\section{Calibration Methods and Application Results for Streamflow and Sediment Yield}

Calibration refers to the process of identifying the "best" set of model parameters that would closely match the model simulated outputs and the observed data. Calibration is commonly performed using trial-and-error process where the modeler changes input parameters one-at-atime and then compares model output with observed data. This manual calibration procedure is time consuming and is less likely to identify optimal set of parameters. To overcome the limitation of this manual procedure, automatic calibration in which optimization algorithms are integrated with simulation models and used to thoroughly search for optimal parameters, is increasingly being used to calibrate comprehensive watershed simulation models such as SWAT (Duan et al. (1992), Muleta and Nicklow (2005), Tolson and Shoemaker (2007)). In this study, four optimization methods: Genetic Algorithms (Holland, 1975), Shuffled Complex EvolutionUniversity of Arizona (Duan et al., 1992) as currently implemented in SWAT, Parameter ESTimation (PEST) (Doherty, 2004), and Dynamically Dimension Search (DDS) (Tolson and Shoemaker, 2007) have been used to automatically calibrate streamflow and sediment yield for the Morro Bay watershed. The methods are compared in terms of their effectiveness in improving accuracy of the simulated output and in terms of their computational efficiency. The four optimization methods have been selected because of their popularity in calibrating watershed simulation models and based on results of comparative studies that have been reported in the literature. For brief description of the optimization methods used in this study the reader is referred to Muleta (2010).

The calibration methods were applied to the Morro Bay watershed to calibrate streamflow at Canet Road station using data from 1995-1998. Sediment yield was calibrated using the data collected by the paired watersheds study from 1992-2001 at Walters Creek station. No BMPs were installed in the Walters Creek watershed implying that the parameter values identified by the calibration process would apply to the subwatersheds with no BMPs. For GAs, SCE-UA, and the DDS algorithms, a maximum of 5000 model evaluations was used. PEST does 
not use maximum iteration as stopping criterion. Five calibration runs were made for each of the four methods which is a total of twenty calibration runs. As performance of the calibration methods largely depends on values used for the user specified parameters of the respective algorithm, all such parameters were set to their default or commonly used values. Sum of square of residuals between model simulated and observed outputs was used as objective function. Calibration results obtained by the four methods are summarized in Table 2. Graphical comparison of the results obtained for streamflow using PEST is given in Figure 2, and sediment yield results obtained at Walters Creek station is given in Figure 3. Table 1 shows that PEST and DDS outperformed SCE-UA and GAs in terms of effectiveness as well as efficiency. PEST needed only 120 evaluations to produce the results shown in the table. DDS was the second efficient as it needed less than 2000 simulation to converge. Based on these results, one can conclude that PEST is by far the most efficient and it also performed better than GAs, SCE-UA and DDS. All four methods produced good results compared to past studies that used SWAT to model watersheds in arid and semi-arid regions (Van Liew et al., 2007). More detailed comparative study is being done to confirm the results reported here.

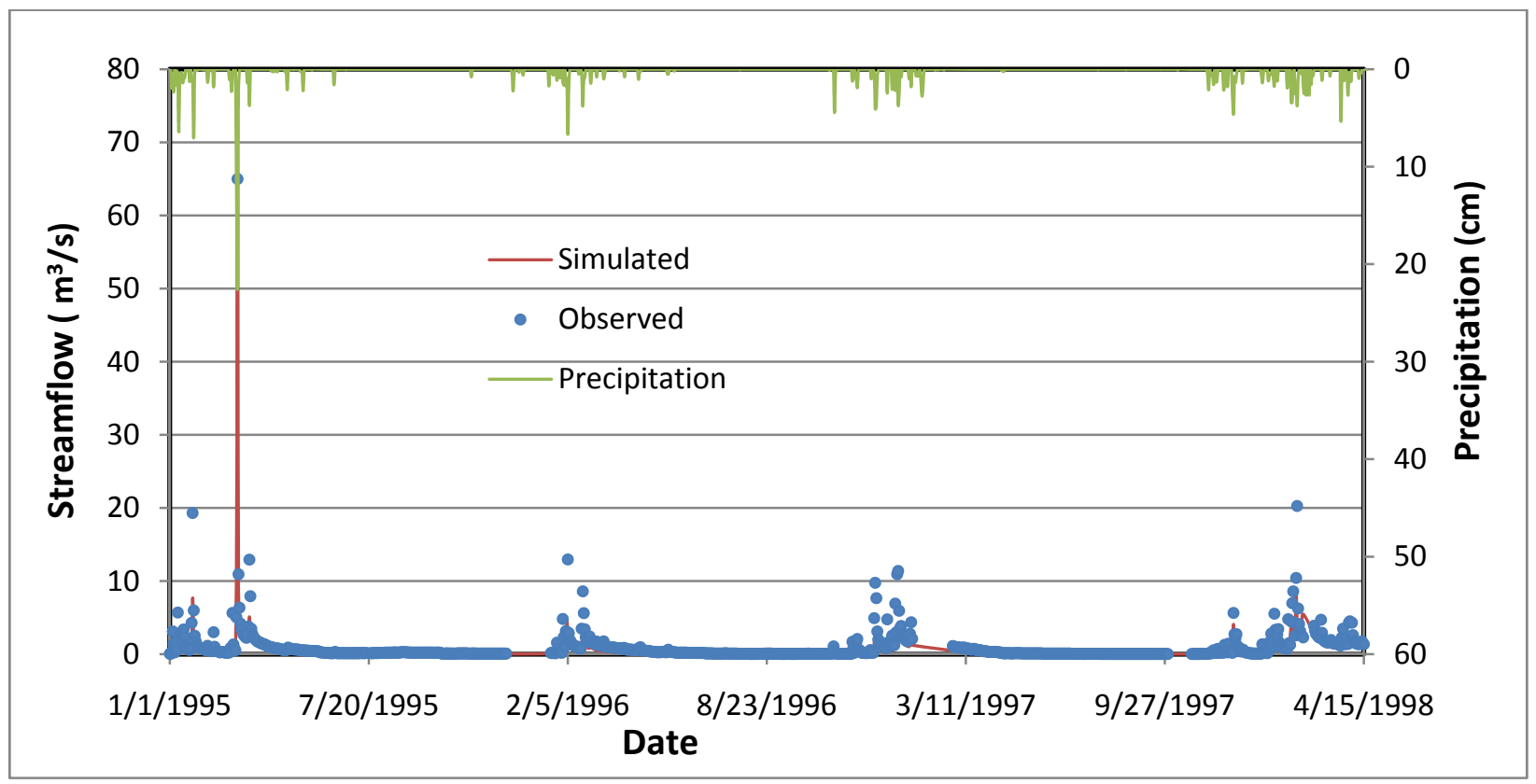

Figure 2: Comparison of Simulated and Observed Streamflow for Canet Road

Table 2: Calibration Results Obtained Using Four Optimization Methods

\begin{tabular}{|l|c|c|c|c|}
\hline \multicolumn{1}{|c|}{ Statistics } & GAs & SCE & DDS & PEST \\
\hline $\begin{array}{l}\text { Mean Sum of Square } \\
\text { of Residuals }\end{array}$ & 3542.98 & 4022.1 & 3420.62 & 3419.0 \\
\hline Average $\boldsymbol{E}_{\boldsymbol{f}}$ & 0.5272 & 0.5657 & 0.5419 & 0.5466 \\
\hline
\end{tabular}




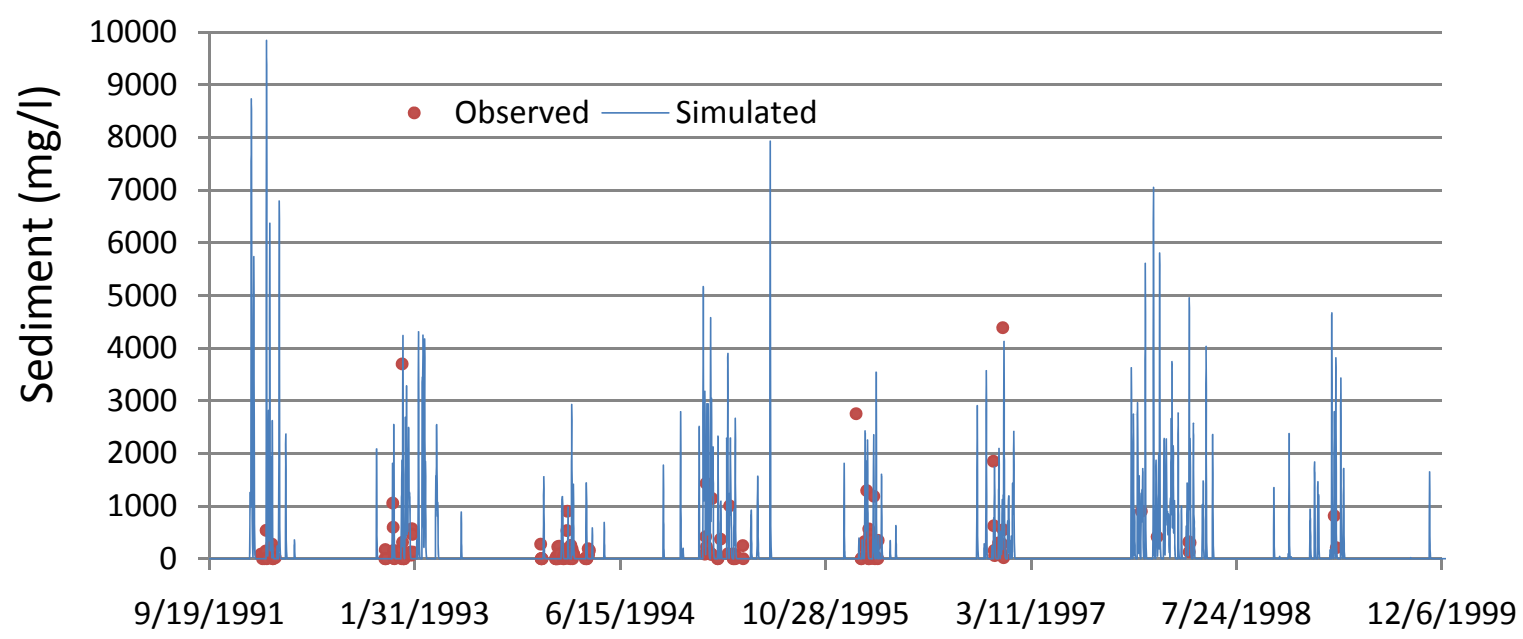

Figure 3: Comparison of Simulated and Observed Sediment for Walters Gauging Station

\section{Effectiveness of the BMPs Installed in the Chorro Creek Watershed}

The "optimal" SWAT parameters identified by the calibration effort were applied to all subwatersheds in the Morro Bay watershed to estimate sediment yield that would have been produced from the entire watersheds if no BMPs were installed. To estimate sediment yield from the watershed for the post-BMP implementation scenario, SWAT parameters that were believed to be affected by the BMPs installed in the specific subwatershed were modified guided by literature (Arabi et al. (2007), Bracmort et al. (2006)). As the major BMPs were installed before 1998, the post BMP scenario simulation was done for the 1998-2008 period. Annual average sediment yield values obtained for the with $B M \mathrm{P}$ and the without $B M P$ scenarios were compared to evaluate effectiveness of the BMPs that were designed to reduce erosion. As described in the previous sections, sediment transport behavior of the stream channels in the lower part of the watershed is not calibrated in this study due to lack of sediment data at the lower reaches of the watershed. In spite of this accuracy issue with regard to the sediment that gets to the mouth of the watershed where the Chorro Flats project is located, effectiveness of the Chorro Flats project was also evaluated based on sediment yield estimates obtained at the upstream and the downstream ends of the project. To model the Chorro Flat project, the stream channel that passes through the project was modified to make it shallower and milder to allow overflow of the main channel. Slope of the subwatershed was also reduced to enable deposition of sediment in the flat. For cattle exclusion projects and channel stabilization projects, model parameters that simulate erodibility of the channel were modified. For grazing management operations, management operation file was modified for the respective subwatersheds.

For the Chorro Creek watershed, average annual sediment yield obtained was 2.9 tons/ha and 3.15 tons/ha for the with BMP and the without BMP scenarios, respectively. This shows about 9 percent reduction in sediment yield from the entire Chorro Creek watershed due to the BMPs implemented in Chumash Creek watershed, the cattle exclusion project in Dairy Creek watershed, the cattle exclusion project downstream of Chorro reservoir and the grazing management project in the San Bernardo Creek watershed. Improvement in sediment reduction achieved at the local subwatersheds where the BMPs are installed is as high as 50 percent. Most of these BMP projects would also help reduce erodibility of stream banks and could decrease sediment that leaves the subwatershed. This role is not factored in the 9 percent figure indicated 
here. It should also be noted that average sediment yield estimated for the 1998-2008 period is lower than estimates reported by previous studies done for the watershed (Tetra Tech, 1998). However, for another simulation duration (i.e., 1992-2001) average sediment yield was found to be 4.46 tons/ha. This figure compares well with sediment yield estimated for Chorro Creek watershed estimated by Tetra Tech (1998). It is believed that the 1998-2008 sediment yield was lower because of rainfall characteristics of the period.

Effectiveness of the Chorro Flat project was analyzed by comparing sediment estimates at the upstream and the downstream ends of the Flat considering the with project and the without project scenarios. Results indicate that if no project were implemented, sediment leaving the channel where the flat is installed would be 60 percent of the sediment that enters it. With the flat project implemented, sediment leaving the channel is estimated as 38 percent of the sediment that enters the channel. Therefore, according to the model, implementation of the Chorro Flat project has resulted in $22 \%$ reduction in the sediment that enters the estuary from the Chorro Creek watershed. Interestingly, this estimate is very close to the $23 \%$ reduction estimated by CSLCRCD (2002). However, it should be noted that the sediment routing component of the model was not calibrated for the watershed. As such, actual sediment figures estimated by the model for the lower portion of the watershed may not be reliable.

\section{Conclusions}

BMP effectiveness study was carried for the Morro Bay watershed. SWAT was used to model streamflow and sediment yield for the watershed. Model evaluation steps were carried out to improve accuracy of the model simulation. Two sensitivity analysis methods, OAT and SMR, have been used to determine the most influential parameters of SWAT that need to be calibrated. Four automatic calibration methods have also been compared in terms of their efficiency and effectiveness. The calibration comparison showed that PEST, a gradient based local search method outperformed global optimization methods including GAs, SCE-UA, and DDS. The calibrated model was used to simulate the effect of BMPs on sediment yield. Results indicate that the BMPs have significantly reduced sediment yield at local subwatersheds as well as the sediment that enters the bay. As an ongoing study, additional watershed information will be collected and used to further improve accuracy of the sediment deposition and scouring behavior

of the stream channels in the watershed.

\section{References}

Arabi, M., Frankenberger, J. R., Engel, B. A., and Arnold, J. G. (2007). "Representation of agricultural conservation practices with SWAT", Hydrol. Process., DOI: 10.1002/hyp.6890

Arnold, J.G., Williams, J.R., Srinivasan, R., and King, K.W. (1999). SWAT: Soil and Water Assessment Tool. U.S. Dept. of Agriculture, Agricultural Research Service, Temple, TX.

Beven, K.J. and Freer, J. (2001). "Equifinality, Data Assimilation, and Uncertainty Estimation in Mechanistic Modeling of Complex Environmental Systems Using the GLUE Methodology." J. of Hydrology, 249: 11-29.

Bracmort, K. S., Arabi, M., Frankenberger, J. R., Engel, B. A., and Arnold, J. G. (2006). "Modeling Long-Term Water Quality Impact of Structural BMPs." Transactions of the $A S A B E, 49(2): 367-374$. 
CCRWQCB (2002). "Morro Bay Total Maximum Daily Load for Sediment (including Chorro Creek, Los Osos Creek and the Morro Bay Estuary)." State of California Central Coast Regional Water Quality Control Board, San Luis Obispo, California.

CSLRCD(2002). "Chorro Flats Enhancement Project, Final Report to the California State Coastal Conservancy."

Doherty, J. (2004). PEST: Model-Independent Parameter Estimation, User Manual, 5th ed., Watermark Numer. Comput., Brisbane, Queensland, Australia.

Duan, Q., Sorooshian, S., and Gupta, V.K. (1992). "Effective and efficient global optimization for conceptual rainfall-runoff models." Water Resour. Res., 28(4): 1015-1031.

Gallagher, M., and J. Doherty (2007). Parameter estimation and uncertainty analysis for a watershed model, Environ. Modell. Software, 22(7), 1000-1020.

Griensven, A. v, T. Meixner, S. Grunwald, T. Bishop, M. Diluzio, and R. Srinivasan (2006). A global sensitivity analysis tool for the parameters of multi-variable catchment models. $J$. Hydrology, 324, 10-23.

Holland, J.H. (1975). Adaptation in Natural and Artificial Systems. University of Michigan Press, Ann Arbor, MI.

Matott, L. S., J. E. Babendreier, and S. T. Purucker (2009). Evaluating uncertainty in integrated environmental models: A review of concepts and tools, Water Resour. Res., 45, W06421, doi:10.1029/2008WR007301.

Morris, M.D. (1991). Factorial sampling plans for preliminary computational experiments. Technometrics 33(2).

Muleta, M.K. (2010). "Comparison of Model Evaluation Methods to Develop a Comprehensive Watershed Simulation Model." Proceedings of the 2010 Conference of the Environmental and Water Resources Institute, ASCE, Providence, Rhode Island, May 1620.

Muleta, M.K. and Nicklow, J.W. (2005). "Sensitivity and Uncertainty Analysis Coupled with Automatic Calibration for a Distributed Watershed Model." J. Hydrology, 306: 127-145.

Neitsch, S.L., Arnold, J.G., Kiniry, J.R., and Williams, J.R. (2005). Soil and Water Assessment Tool Theoretical Documentation. Version 2005. Grassland, soil and water research service, Temple, TX.

Skahill, B.E. and J. Doherty (2006). Efficient accommodation of local minima in watershed model calibration, J. of Hydology, 329, 122- 139, doi:10.1016/j.jhydrol.2006.02.005.

Tetra Tech (1998). Morro Bay National Estuary Program: Sediment Loading Study. Lafayette, California.

Tolson, B. A., and C. A. Shoemaker (2007). Dynamically dimensioned search algorithm for computationally efficient watershed model calibration, Water Resour. Res., 43, W01413, doi:10.1029/2005WR004723.

U.S. EPA (2002). Guidance for quality assurance project plans for modeling. EPA QA/G-5M. Report EPA/240/R-02/007. Washington, D.C.: U.S. EPA, Office of Environmental Information.

Van Liew,M.W., Veith, T.L., David D. Bosch, D.B. and Arnold, J.G. (2007). Suitability of SWAT for the Conservation Effects Assessment Project: Comparison on USDA Agricultural Research Service Watersheds. J. Hydrologic Engineering, 12:2(173). 